\title{
Determination of Sex from Epicondylar Breadth of Femur
}

\author{
Rakesh K. Vora ${ }^{1}$, Shailesh M. Patel ${ }^{2}$ \\ ${ }^{1}$ Assistant Professor, Department of Anatomy, Dr. M.K.Shah Medical College and Research Centre, Ahmedabad, Gujarat, ${ }^{2}$ Professor \& Head, Department \\ of Anatomy, Government Medical College, Bhavnagar, Gujarat.
}

\section{Abstract}

Introduction: Sex determination from skeletal remains allows one to narrow the search in individual identification. As the femur shows 75\% Variation between individuals, it has been useful for sex determination. There are many possible femoral measurements, but the Epicondylar breadth is routinely considered to be useful for sexing individuals. To date, nothing has been published on other measurements of distal femur, which may be useful if the bone is fragmented, and only lower part of bone is available. This study is an attempt to evaluate sex determination from distal femora of Indian origin. Subjects and Methods: For this study total 208 normal dry human femur bones of known sex were studied, which were collected from various medical colleges of Gujarat. For measurement of Epicondylar breadth of femur, Digital sliding vernier caliper was used. Results: The discriminant function equation for sex determination from Epicondylar Breadth (EB) of femur is:- $\mathrm{Y}=0.143 * \mathrm{~EB}+(-8.334)$ If $\mathrm{Y}$ is $<0$ then the sex of the bone is Female and if $\mathrm{Y}$ is $>0$ then the sex of the bone is Male. Conclusion: With the use of discriminant function score, $87 \%$ of femur samples are correctly predicted about sex. The results of this study is particularly useful in a case for sex determination in which the skeletal remains of an individual are incomplete or damaged and thus more accurate bones such as the pelvis or cranium are absent.

Keywords: Femur, Sex determination, Epicondylar breadth.

Corresponding Author: Dr. Shailesh M. Patel, Professor \& Head, Department of Anatomy, Government Medical College, Bhavnagar 364001, Gujarat, India.

Received: March 2019

Accepted: March 2019

\section{Introduction}

Sex determination from skeletal remains allows one to narrow the search in individual identification. The pelvis and skull are the two most sexually dimorphic elements in the skeleton. $^{[1,2]}$ And other than these two bones, sexual dimorphism is also studied from the tibia, ${ }^{[3]}$ mandible, ${ }^{[4]}$ humerus and many other bones. But these elements may not be available for evaluation for every condition. The femur is one of the most robust bones in the skeleton and although it is less accurate than a skull or os coxae for sexing, it is frequently recovered from archaeological and crime scene excavations. ${ }^{[5]}$

The femur is used by Anthropologists for many different applications. Paleoanthropologists Use the femur to determine stature and locomotion patterns. More specifically, because the femur shows $75 \%$ Variation between individuals, it has been useful for sex determination. ${ }^{[6-13]}$ Sex determination has been accomplished using a variety of femoral dimensions. Many of the above methods for sex determination from the femur are dependent on the presence of well preserved (mostly complete) femora; unfortunately, this is often not seen in badly decomposed forensic remains. Femoral Shafts are most commonly encountered in forensic situations.
Data concerning the sexing potential of the femur are available in the literature and it is well known that these data vary a great deal according to the population sample from which they were taken. There are many possible femoral measurements, but the epicondylar breadth is routinely considered to be useful for sexing individuals. The study of an isolated measurement like the epicondylar breadth may be of interest in cases of partial, badly preserved, fragmentary remains or cremains, especially when the superior epiphysis, recognized as a good sex estimator, is absent. Furthermore, previous research has indicated that, for sex determination from long bones, longitudinal distances such as lengths are often less discriminating than breadth and circumference.

Citing the example of the femur, studies have been reported on various populations including the Chinese;6,7 Spanish; ${ }^{[12]}$ Nigerians;Croatians, ${ }^{[14]}$ Thais; ${ }^{[11]}$ South African whites and blacks, ${ }^{[15,16]}$ and Germans. ${ }^{[8]}$ Nakahashi and Nagai, ${ }^{[17]}$ Tagaya, ${ }^{[18]}$ Yoshino and Kato et al. ${ }^{[19]}$ and Sakaue, ${ }^{[20]}$ studied sex determination from various bones in both recent and prehistoric Japanese populations.

Little work on the subject has been reported from India except for the study by Singh and Singh (1972A and $1972 B),{ }^{[21,22]}$ on the head of femur, the study by Ruma Purkait on proximal femur, ${ }^{[23]}$ the study by Rashmi Shrivastava(2012), ${ }^{[25]}$ and Gargi Soni $(2010),{ }^{[26]}$ on various 


\section{Vara d Patel; Determination of Sex fram Epicandylar Breadth of Femur}

measurements of femur. To date, nothing has been published on other measurements of distal femur, which may be useful if the bone is fragmented, and only lower part of bone is available. This study is an attempt to evaluate sex determination from distal femora of Indian origin.

This study on sex determination is based on the principle that the axial skeleton weight of the male is relatively and absolutely heavier than that of the female, ${ }^{[27]}$ and the initial impact of this weight is borne by the femur in transmission of the body weight. Another factor that makes its indentation on the femur is the modification of the female pelvis with respect to its specialized function of reproduction. Therefore, the stress and strain experienced by the femur is different in a male than it is in a female.

The factors that makes the femur different in male and female are as follows; the axial skeletal weight of the male is relatively and absolutely larger than that of the female and the most of this weight is borne directly by the femur in transmission of the body weight; and obvious modification of the female pelvis with respect to its specialized function in reproduction. Some of the powerful methods of sex determination from skeletal element are based upon the application of statistical analysis to osteological material. Discriminate function analysis is one of the sophisticated mathematical approaches. Long bones are especially favorable for metric analysis. In this regard the femur bone has been studied most extensively. Methods of sex determination by discriminate analysis from the adult femur have been described in several populations by many authors.

\section{Subjects and Methods}

For this study total 208 normal dry human femur bones of known sex were studied. These femur bones were collected from various medical colleges of Gujarat. Out of 208 bones, 60 bones obtained from Government Medical College, Bhavnagar; 08 bones obtained from B.J. Medical College, Ahmedabad; 08 bones obtained from Smt. N.H.L. Municipal Medical College, Ahmedabad; 14 bones obtained from GMERS Medical College, Sola, Ahmedabad; 12 bones obtained from GCS Medical College, Ahmedabad; 30 bones obtained from Pramukhswami Medical College, Karamsad; 68 bones obtained from GMERS Medical College, Dharpur, Patan; and 08 bones obtained from College of Medical Science, Amargadh. Among 208 femur bones, 150 are of male and 58 are of female, 104 are of Right side and 104 of Left side. The femur bones were undamaged and without pathological alterations. Any femur exhibiting signs of disease such as cortical bone deterioration, extreme osteophytic activity, diffuse osteoarthritis or prosthesis, was excluded from the study. Bones with any injury, deformity or artifact were also discarded. A thorough visual inspection was done keeping the bone on Anthropometry board with graph paper.

For measurement of variables, Digital sliding vernier caliper (with an accuracy of $+0.05 \mathrm{~mm}$ ) was used.

The following parameter of the Femur bone was considered:

\section{Epicondylar breadth}

Distance between the two most laterally projecting points on the epicondyles parallel to the infracondylar plane. The measurement was taken with the bar of the calliper touching the point of both epicondyli in the infracondylar plane and the arms of the calliper touching respectively the lateral condyle of the femur and the medial condyle of the femur. The measurement was repeated three times at three different sessions by the same observer, using the resulting mean value to reduce intra-observer error. After collecting data, in order to assess bilateral variation in the measurements, the measurements of femora were subjected to a paired t-test. Statistical functions carried out included univariate analyses for sex and epicondylar breadth. For classification purposes, a discriminant function analysis was used to study sexual dimorphism in this population.

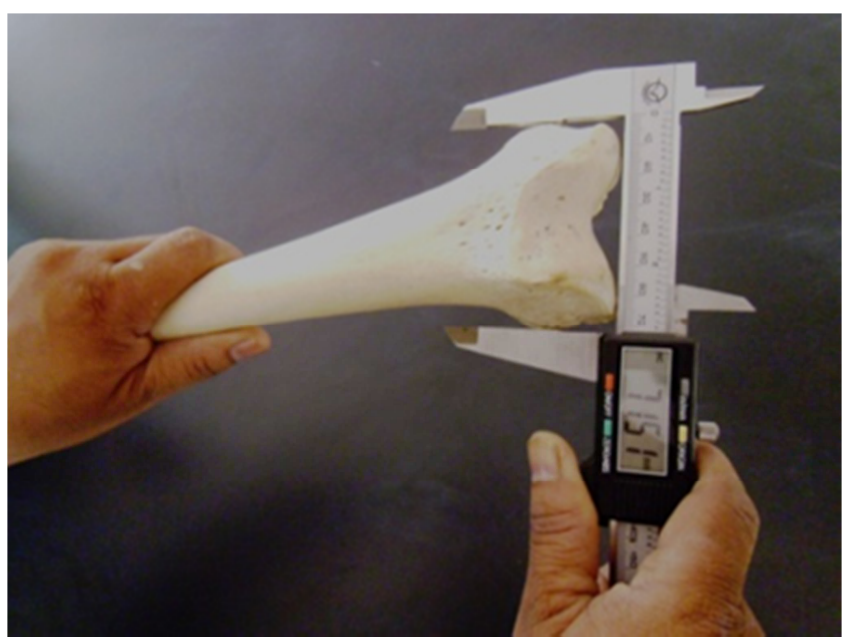

Figure 1: Measurement of epicondylar breadth of femur using digital sliding vernier caliper.

\section{Results \& Discussion}

Total 208 Femur bones were examined for this study, among which 150 are of male and 58 are of female. Epicondylar Breadth and Total Femoral Length of Femur bones were measured (in mm with 2 decimal).

The statistical data which were extracted from the calculation and analysis are tabulated in [Table 1 to Table 4] to show different parameters at a glance.

[Table 1] shows the descriptive statistics of Epicondylar Breadth (EB) and [Table 2] shows sex-wise distribution of Epicondylar Breadth (EB).

Table 1: Descriptive Statistics of Epicondylar Breadth (EB) in mm

\begin{tabular}{|l|l|l|l|l|l|}
\hline & N & Min. & Max. & Mean & $\begin{array}{l}\text { Std. } \\
\text { Deviation }\end{array}$ \\
\hline $\begin{array}{l}\text { Epicondylar } \\
\text { Breadth(mm) }\end{array}$ & 208 & 40.65 & 82.14 & 67.21 & 10.88 \\
\hline
\end{tabular}

Table 2: Sex-wise descriptive statistics of Epicondylar Breadth (EB) in mm

\begin{tabular}{|c|c|c|c|c|c|}
\hline & Sex & $\mathbf{N}$ & Mean & $\begin{array}{l}\text { Std. } \\
\text { Deviation }\end{array}$ & $\begin{array}{l}\text { Std. } \\
\text { Error } \\
\text { Mean }\end{array}$ \\
\hline \multirow{2}{*}{$\begin{array}{l}\text { Epicondylar } \\
\text { Breadth }(\mathrm{mm})\end{array}$} & $\mathrm{F}$ & 58 & 56.6496 & 11.375 & 1.4939 \\
\hline & $\mathrm{M}$ & 150 & 71.2965 & 7.4077 & 0.6048 \\
\hline \multirow{2}{*}{$\begin{array}{l}\text { Total Femoral } \\
\text { Length }(\mathrm{mm})\end{array}$} & $\mathrm{F}$ & 58 & 417.9066 & 13.3859 & 1.7576 \\
\hline & $\mathrm{M}$ & 150 & 436.6933 & 17.2354 & 1.4072 \\
\hline
\end{tabular}




\section{Vara d Patel; Determination of Sex fram Epicandylar Breadth of Femur}

To find out sexual dimorphism of Epicondylar Breadth of femur, independent-sample t test was applied. Results of independent-sample t test as shown in [Table 3] indicates highly significant $(\mathrm{p}<0.0001)$ t-value for Epicondylar Breadth. So sex determination from the Epicondylar Breadth measurements is highly indicated.

\begin{tabular}{|c|c|c|c|c|c|c|c|}
\hline \multicolumn{8}{|c|}{ Table 3: Independent-sample t test for Epicondylar Breadth } \\
\hline & \multicolumn{7}{|c|}{ t-test for Equality of Means } \\
\hline & \multirow[t]{2}{*}{$\begin{array}{l}t \\
\text { val } \\
\text { ue }\end{array}$} & \multirow[t]{2}{*}{ df } & \multirow[t]{2}{*}{$\begin{array}{l}\text { Sig. } \\
(2- \\
\text { taile } \\
\text { d) }\end{array}$} & \multirow[t]{2}{*}{$\begin{array}{l}\text { Mean } \\
\text { Differe } \\
\text { nce }\end{array}$} & \multirow[t]{2}{*}{$\begin{array}{l}\text { Std. } \\
\text { Error } \\
\text { Differe } \\
\text { nce }\end{array}$} & \multicolumn{2}{|c|}{$\begin{array}{l}95 \% \\
\text { Confidence } \\
\text { Interval o } \\
\text { the } \\
\text { Difference }\end{array}$} \\
\hline & & & & & & $\begin{array}{l}\text { Low } \\
\text { er }\end{array}$ & $\begin{array}{l}\text { Upp } \\
\text { er }\end{array}$ \\
\hline $\begin{array}{l}\text { Epicond } \\
\text { ylar } \\
\text { Breadth } \\
(\mathrm{mm}) \\
\end{array}$ & $\begin{array}{l}10.9 \\
01\end{array}$ & $\begin{array}{l}20 \\
6\end{array}$ & $\begin{array}{l}0.00 \\
0\end{array}$ & -14.65 & 1.34 & $\begin{array}{l}- \\
17.3 \\
0\end{array}$ & $\begin{array}{l}- \\
12.0 \\
0\end{array}$ \\
\hline
\end{tabular}

Where $\mathrm{t}$ value $=$ computed test specific, $\mathrm{df}=$ degrees of freedom, and Sig. $(2$ tailed $)=$ $\mathrm{p}$-value corresponding to the given test specific \& degrees of freedom

Now discriminant function analysis by stepwise method was done for Epicondylar Breadth of femur as shown in [Table 4], and the discriminant function equation is derived. The sex can be determined from this formula by multiplying the value of each measurement of Epicondylar Breadth of femur with its corresponding coefficient ( $\beta$ coefficient) and adding the constant shown in [Table 4]. The discriminant function equation for sex determination from Epicondylar Breadth of femur is:-

$\mathrm{Y}=0.143 * \mathrm{~EB}+(-8.334)$

Where, $\mathrm{Y}=$ Discriminant function score, and $\mathrm{EB}=$ Epicondylar Breadth.

If $\mathrm{Y}$ is $<0$ then the sex of the bone is Female and if $\mathrm{Y}$ is $>0$ then the sex of the bone is Male.

There have been few studies on Indian samples in which sex is determined from femur. ${ }^{[24-26]}$ The sexing potential of the epicondylar breadth is well known. The present study has confirmed that for sex determination, the measurements of the Epicondylar Breadth of femur display higher classification accuracy. According to results and with the use of discriminant function score, total 181 out of 208 femur samples are correctly determined about sex $(87 \%$ accuracy). Among which 39 out 58 female samples and 142 out of 150 male samples are correctly predicted (female: $67.2 \%$ accuracy, male: $94.7 \%$ accuracy).

Table 4: Discriminant function analysis of Epicondylar Breadth of femur

\begin{tabular}{|l|l|l|l|l|l|l|l|}
\hline & $\boldsymbol{\beta}$ coefficient & S.E. & df & Sig. & \multirow{2}{*}{ Exp (B) } & \multicolumn{2}{|l|}{ 95\% Confidence Interval for Exp(B) } \\
\cline { 5 - 9 } & & & & & & Lower & 1.200 \\
\hline Epicondylar Breadth $(\mathrm{mm})$ & 0.143 & 0.020 & 1 & 0.000 & 1.154 & 1.109 & \\
\hline Constant & -8.334 & 1.292 & 1 & 0.000 & 0.000 & & \\
\hline
\end{tabular}

Where S.E. $=$ standard error, $\mathrm{df}=$ degrees of freedom, Sig. $=\mathrm{p}$-value corresponding to the given test specific \& degrees of freedom

Table 5: Comparison of Epicondylar Breadth of femur between different studies and present study

\begin{tabular}{|c|c|c|c|c|c|c|}
\hline \multirow[t]{2}{*}{ Sr. No } & \multirow[t]{2}{*}{ Workers \& Year } & \multirow[t]{2}{*}{ Population } & \multirow[t]{2}{*}{ Sample size } & \multicolumn{2}{|c|}{ Mean+SD $(\mathrm{mm})$} & \multirow[t]{2}{*}{ Accuracy (\%) } \\
\hline & & & & Male & Female & \\
\hline 1 & G.J. Trancho 1997, ${ }^{[12]}$ & Spanish & 132 & $80.6 \pm 2.9$ & $70.8 \pm 2.3$ & 97.5 \\
\hline 2 & V. Alunni-Perret $2008,{ }^{[13]}$ & French & 88 & $84.3 \pm 3.6$ & $74.8 \pm 2.5$ & 95.4 \\
\hline 3 & M.Y. Iscan $1995,,^{[7]}$ & Chinese & 87 & $80.3 \pm 4.2$ & $70.6 \pm 3.2$ & 94.9 \\
\hline 4 & C.A. King $1998,{ }^{[11]}$ & Thai & 104 & $79.7 \pm 3.6$ & $70.0 \pm 3.3$ & 93.3 \\
\hline 5 & Ismail Ozer 2008, ${ }^{[9]}$ & Japanese & 43 & $78.2 \pm 2.8$ & $69.2 \pm 5.5$ & 93.0 \\
\hline 6 & M. Slaus $2003,{ }^{[14]}$ & Croatian & 195 & $86.7 \pm 4.3$ & $75.1 \pm 4.1$ & 91.3 \\
\hline 7 & M. Steyn $1997,{ }^{[15]}$ & White South African & 106 & $84.6 \pm 4.6$ & $75.1 \pm 3.3$ & 90.5 \\
\hline 8 & L. Wu $1989,{ }^{[6]}$ & Chinese & 141 & $77.8 \pm 5.8$ & $69.3 \pm 3.0$ & 83.7 \\
\hline 9 & G. Mal 2000, ${ }^{[18]}$ & German & 170 & $84.0 \pm 10$ & $77.0 \pm 5.0$ & 81.4 \\
\hline 10 & S.A. Asala $2004,{ }^{[10]}$ & Black South African & 216 & $78.9 \pm 3.7$ & $71.8 \pm 4.8$ & 81.5 \\
\hline 11 & R. Purkait $2004,{ }^{[24]}$ & Indian & 124 & $78.7 \pm 4.5$ & $66.8 \pm 4.2$ & 90.3 \\
\hline 12 & R. Srivastava $2012,{ }^{[25]}$ & Indian & 102 & $76.8 \pm 4.1$ & $68.2 \pm 4.0$ & 83.6 \\
\hline 13 & Present Study & Indian & 208 & $71.3 \pm 7.4$ & $56.6 \pm 11.4$ & 87.0 \\
\hline
\end{tabular}

Single postcranial osteometric measurements may be of interest when only fragmented skeletal remains are available, and several investigators assessed that the use of discriminant functions based on several variables does not always significantly improve the prediction obtained by using a single variable. A review of the literature shows that there is considerable intra- and inter-population variability in femoral dimensions and standard formulae cannot be transposed from one population to another. In this study, we first attempted to evaluate sexual dimorphism from the measurement of the epicondylar breadth in Indian population sample, and secondly, we analyzed the geographical accuracy of this specific variable.

In all groups, a substantial part of the over-50 population suffers from osteoarthritis of the knees. However, the literature states that osteoarthritis occurs on the tibio-femoral and the patello-femoral surfaces. Our work consisted in analyzing the anthropometric characteristics of the medial and lateral condyles of the femur. There is no articular cartilage on the medial and lateral epicondyles, and so these are not affected by osteoarthritis. ${ }^{[28]}$ Another study determined that knee height (the distance from the sole of the foot to the anterior surface of the thigh while the ankle and the knee are both flexed at a right angle) did not vary significantly with age.

Samples of Epicondylar Breadth of femur have routinely been used for sexing individuals, and often provided the best measure of sex determination. Comparison of Epicondylar Breadth of femur between present study and other studies has been shown in [Table 5]. 


\section{Vara d Patel; Determination of Sex fram Epicandylar Breadth of Femur}

The highest rate of accuracy for sexual determination using the distal epicondylar breadth of the femur is obtained in the Spanish population (97.5\%).12 In the French population, ${ }^{[13]}$ South African white population, ${ }^{[15]}$ some Chinese populations, ${ }^{[7]}$ Japanese populations and Thai populations, ${ }^{[9,11]}$ the epicondylar breadth is the most sexually dimorphic element of the femur, yielding better results even than the head diameter.

On the other hand, other populations, such as the Germans, 8 the Croatians and Black South Africans showed a poorer accuracy rate in sexing individuals using epicondylar breadth. ${ }^{[10,14]}$ In the German sample, 8 only $81.4 \%$ of the cases were correctly classified using epicondylar breadth, and the authors did not recommend using this variable alone for sex determination. Furthermore, the overlap between both sexes was greater in that sample. In Black South Africans 10 the vertical head diameter and the medial condylar length were most successful in sex identification from the upper and lower ends of the femur respectively. In the Croatian sample, the maximum diameter of the femoral head was more successful in sexing individuals than the epicondylar breadth. ${ }^{[14]}$

In a Chinese sample, ${ }^{[6]}$ the maximum head diameter was the best factor of discrimination, with an accuracy rate of $85.1 \%$. This success rate is quite low, but some studies have showed that Chinese femora display little sexual dimorphism, leading to lower accuracy rates of sex determination when only a single variable is used. ${ }^{[17]}$ There is a correlation between epicondylar breadth and body size. A higher accuracy rate has been achieved in other Chinese population samples according to Iscan and Ding. ${ }^{[7]}$ This could be understood as intra-population variations from one area of the country to another, ${ }^{[6]}$ especially if there are significant differences in height or robustness between the people. This demonstrates that sexual dimorphism is expressed differently within contemporary populations, and geographical variations are apparent in metric values.

In Indian population study of Ruma Purkait, ${ }^{[2]}$ confirmed that for sex determination the measurements of the femoral extremities display higher classification accuracy (91.993.5\% for head diameters and $90.3 \%$ for epicondylar width) than shaft dimensions. So the study of ruma purkait in Indians showed a poorer accuracy rate in sexing individuals using epicondylar breadth as compared to head diameters. ${ }^{[24]}$ In another north Indian population study of Rashmi Shrivastava, ${ }^{[25]}$ multivariate discriminant function analysis using Epicondylar breadth, Antero-posterior diameter of lateral condyle, and Proximal breadth has produced higher accuracy of $90.2 \%$ (man: $91.5 \%$ and woman: $85.7 \%$ ). But in this study, univariate discriminant function analysis using Epicondylar breadth has produced higher accuracy of $83.7 \%$ as compared to all other measurements used in the study.

\section{Conclusion}

In the present study, total 208 femur bones of known sex (150 male and 58 female) were obtained from various medical colleges of Gujarat. Among these bones, 104 are of right side and 104 are of left side. Epicondylar Breadth of femur bones was recorded with digital sliding vernier caliper.
To find sexual variation of Epicondylar Breadth of femur, independent-sample $t$ test and discriminant function analysis by stepwise method was done. The t-value for Epicondylar Breadth is 10.901 , which was found highly significant $(p<0.0001)$. The discriminant function equation for sex determination from Epicondylar Breadth of femur is:-

$\mathrm{Y}=0.143 * \mathrm{~EB}+(-8.334)$

Where, $\mathrm{Y}=$ Discriminant function score, and $\mathrm{EB}=$ Epicondylar Breadth.

With the use of discriminant function score, $87 \%$ of femur samples (181 out of 208 femur bones) are correctly predicted about sex. The results of this study is particularly useful in a forensic anthropological case for sex determination in which the skeletal remains of an individual are incomplete or damaged and thus more accurate bones such as the pelvis or cranium are absent.

List of Abbreviations used

$\mathrm{EB}=$ Epicondylar Breadth

$\mathrm{Y}=$ Discriminant function score

$\mathrm{M}=$ Male

$\mathrm{F}=$ Female

S.E. = Standard Error

Df $=$ Degrees of freedom

\section{References}

1. Phenice TW. A newly developed visual method of sexing the os pubis. Am J Phys Anthropol, 1969; 30:297-302.

2. Kelley MA. Parturition and pelvic changes. Am J Phys Anthropol, 1979; 51:541-546.

3. Iscan MY, Miller-Shaivitz P. Determination of sex from the tibia. Am J Phys Anthropol. 1984, 64:53-57.

4. Steyn M, Iscan MY. Sexual dimorphism in the crania and mandibles of South African whites. Forensic Sci Int. 1998, 30:916.

5. DiBennardo R, Taylor JV. Classification and misclassification in sexing the black femur by discriminant function analysis. Am J Phys Anthropol. 1982; 58:145-151.

6. Wu L. Sex determination of Chinese femur by discriminant functions. J Forensic Sci. 1989, 34(5):1222-1227.

7. Iscan MY, Ding S. Sexual dimorphism in the Chinese femur. Forensic Sci Int. 1995; 74 (1-2):79-87.

8. Mall G, Graw M, Gehring KD, Hubig M. Determination of sex from femora. Forensic Sci Int. 2000; 113:315-321.

9. Ozer I, Katayama K. Sex Determination Using the Femur in an Ancient Japanese Population. Coll Antropol. 2008; 32(1):67-72.

10. Asala SA, Bidmos MA, Dayal MR. Discriminant function sexing of fragmentary femur of South African blacks. Forensic Science International. 2004; 145:25-29.

11. King CA, Iscan MY, Loth SR. Metric and comparative analysis of sexual dimorphism in the Thai femur. J Forensic Sci. 1998; 43(5):954-958.

12. Trancho GJ, Robledo B, Lopez-Bueis I, Sanchez JA. Sexual determination of the femur using discriminant functions - Analysis of a Spanish population of known sex and age. J Forensic Sci. 1997; 42(2):181-185.

13. Alunni-Perret V, Staccini P, Quatrehomme G. Sex determination from the distal part of the femur in a French contemporary population. Forensic Science International. 2008; 175:113-117.

14. Slaus M, Strinovic D, Skavic J, Petrovecki V. Discriminant function sexing of fragmentary and complete femora: standards for contemporary Croatia. J Forensic Sci. 2003; 48(3):509-512.

15. Asala SA. Sex determination from the head of the femur of South African whites and blacks. Forensic Science International. 2001; 117:15-22.

16. Steyn M, Iscan MY. Sex determination from the femur and tibia in South African whites. Forensic Science International. 1997,90:111- 


\section{Vara d Patel; Determination of Sex fram Epicandylar Breadth of Femur}

119.

17. Nakahashi T, Nagai M. Sex assessment of fragmentary skeletal remains. J Anthropol Soc Nippon. 1986; 94(3):289-305.

18. Tagaya A. J Anthropol Soc Nippon. 1987; 95(1):45

19. Yoshino M, Kato S. J Forensic Sci. 1994; 39(3):785.

20. Sakaue K. Anthropological Science. 2004; 112:75.

21. Singh SP, Singh S. The sexing of adult femora: Demarking points for Varanasi zone. Journal of the Indian Academy of Forensic Sciences. 1972; 11:1- 6 .

22. Singh SP, Singh S. Identification of sex from the head of the femur: The demarking points for Varanasi zone. Indian Medical Gazette. 1972,11:45-49.

23. Purkait R. Triangle identified at the proximal end of femur: a new sex determinant. Forensic Science International. 2005; 147:135139.

24. Purkait R, Chandra H. Study of sexual variation in Indian femur. Forensic Science International. 2004; 146:25-33.

25. Srivastava R, Saini V, Rai RK, Pandey S, Tripathi SK. A Study of Sexual Dimorphism in the Femur among North Indians. J Forensic Sci. 2012; 57(1):19-23.

26. Soni G, Dhall U, Chhabra S. Determination of sex from femur: Discriminant analysis. J Anat Soc India. 2010; 59(2):216-221.

27. William P L, Warwick R, Dyson M, Bannister LH. Gray's Anatomy. Churchill Livingstone Edinburgh. 1989; 850-851.

28. Martin DF. Pathomechanics of knee osteoarthritis. Med Sci Sports Exerc. 1994; 26(12): 1429-1434.

Copyright: () the author(s), publisher. Academia Anatomica International is an Official Publication of "Society for Health Care \& Research Development". It is an open-access article distributed under the terms of the Creative Commons Attribution Non-Commercial License, which permits unrestricted non-commercial use, distribution, and reproduction in any medium, provided the original work is properly cited.

How to cite this article: Vora RK, Patel SM. Determination of Sex from Epicondylar Breadth of Femur. Acad. Anat. Int. 2019;5(1):74-78. DOI: dx.doi.org/10.21276/aanat.2019.5.1.17 